\title{
Rosiglitazone affects the progression of surgically-induced endometriosis in a rat model
}

\author{
SHUN ZHANG ${ }^{1 *}$, LINGLING ZHUANG ${ }^{2 *}$, QIAN LIU ${ }^{2}$, XIAOLIN YU ${ }^{2}$, \\ QINGHUA MIN $^{2}$, MINJIE CHEN ${ }^{3}$ and QI CHEN ${ }^{2}$ \\ Departments of ${ }^{1}$ General Surgery, ${ }^{2}$ Gynecology and Obstetrics, and ${ }^{3}$ Clinical Medicine, \\ The First Affiliated Hospital of Nanchang University, Nanchang, Jiangxi 330006, P.R. China
}

Received June 17, 2020; Accepted September 30, 2020

DOI: $10.3892 / \mathrm{mmr} .2020 .11673$

\begin{abstract}
Endometriosis is closely associated with inflammatory reactions and angiogenesis. Whether PPAR $\gamma$ is a target for the treatment of endometriosis remains unknown. The present study was designed to investigate the impact of a PPAR $\gamma$ agonist (rosiglitazone, RSG) on endometriosis in a rat model and to identify the underlying mechanism. The endometriosis model was established in rats. The pathological state of the endometrium was examined using hematoxylin-eosin staining. The microstructures of interest were visualized using electron microscopy. Western blot analysis and reverse transcription-quantitative polymerase chain reaction were used to detect PPAR $\gamma$ and MAT2A expression. VEGF and caspase-3 expression were investigated using immunohistochemistry. Pathological analysis revealed transparent and red nodules in the model group, and that vasoganglions were present all over the nodules. Endometrial epithelial hyperplasia was observed in the model group, and the shape was columnar. Increased interstitial cell numbers, with compact structure and abundant blood supply, were detected in the model group. Compared with the model group, incomplete epithelial structures with sparse interstitial cells and loose structure were observed in the pathological images from RSG treatment groups. Numerous inflammatory cells and poor blood supply were observed in the endometrial tissues, and the gland was filled mostly with vacuolar cells. Electron microscopy revealed that the tissue structure was integrated. Many vacuoles were formed within the endometrial tissue and the classical morphological changes of apoptotic cells were observed in RSG-treated groups. Caspase-3 and PPAR $\gamma$ expression increased and expression of VEGF and MAT2A decreased in RSG-treated groups. Taken
\end{abstract}

Correspondence to: Dr Qi Chen, Department of Gynecology and Obstetrics, The First Affiliated Hospital of Nanchang University, 17 Yongwai Zheng Street, Nanchang, Jiangxi 330006, P.R. China E-mail: chenqi_112cq@126.com

${ }^{*}$ Contributed equally

Key words: PPAR $\gamma$, MAT2A, endometriosis, rosiglitazone together, these results revealed that RSG impacts the development and progression of endometriosis likely by inhibiting angiogenesis and inducing apoptosis.

\section{Introduction}

Endometriosis is a progressive disease that critically impacts the physical and psychological health of females. Endometriosis may also lead to, or be a cause of, infertility. The symptoms of endometriosis can only be temporarily improved, and endometriosis has a high reoccurrence rate (1). Therefore, it is of great clinical significance and social value to develop drugs with novel mechanisms and improved efficacy for endometriosis treatment. Immunological tolerance is involved in the paroxysm of endometriosis, and would be induced because the ectopic endometrium is not eliminated by the immune system (2). Enhanced macrophage activity and attenuated cellular immune function are commonly observed in endometriosis, particularly including the dysfunction of the cytotoxic reaction mediated by $\mathrm{T}$ cells and natural killer cells. The factors released by macrophages, including prostaglandins, cytokines and growth factors, may induce ectopic endometrium growth. These results indicated that ectopic endometrial growth may be inhibited by decreasing macrophage activity (3).

PPAR $\gamma$ is involved in multiple physiological and pathological processes, including lipid metabolism, glucose metabolism, cell proliferation and differentiation, tumorigenesis, inflammation, and immune responses. Recently, the effects of PPAR $\gamma$ on gynecological disease have gained increasing amounts of attention. PPAR $\gamma$ is expressed in the endometrium (4), and activating PPAR $\gamma$ may lead to inflammatory inhibition and anti-angiogenesis effects (5). As endometriosis is associated with inflammation and angiogenesis, PPAR $\gamma$ may become a novel target for endometriosis treatment (6). Liu et al (7) reported that macrophage activity and proliferation was inhibited by PPAR $\gamma$ endogenous ligands in a dose-dependent manner (7). Additionally, the inhibitory effect of PPAR $\gamma$ activation on ectopic endometrial growth is associated with the inhibition of the activity and proliferation of macrophages within the endometriosis lesion (4). Rosiglitazone (RSG), a PPAR $\gamma$ agonist, not only inhibits the progress of endometriosis (8), but also reduces the symptoms (9). 
The present study examine the effects of RSG on the development and progression of endometriosis in a rat model. The results presented here will allow for deeper understanding of the mechanism of endometriosis, its treatment, and the identification of improved clinical diagnostic markers.

\section{Materials and methods}

Ethic statements. All animal experiments were authorized by the Ethical Committee of The First Affiliated Hospital of Nanchang University and performed following the guidelines for the care and use of laboratory animals and the principles of laboratory animal care and protection.

Preparation of an endometriosis model in rats. Female rats ( $\mathrm{n}=30$; weight $\sim 220 \mathrm{~g} ; 3$ months) were purchased from Hunan SJA Laboratory Animal Co., Ltd and housed in a specific pathogen-free environment that was automatically maintained at a temperature of $23 \pm 2^{\circ} \mathrm{C}$, a relative humidity of $45-65 \%$, and with a controlled $12 \mathrm{~h} \mathrm{light/dark} \mathrm{cycle.} \mathrm{The} \mathrm{animals} \mathrm{had} \mathrm{free} \mathrm{to}$ access food and water. The endometriosis model was prepared as previously described (10). The estrous cycles of rats were confirmed by vaginal smears. The rats in estrus were anesthetized by isoflurane (5\%) and fixed on the operating table. Iodophor was uniformly smeared over the abdomen, which was then cut open to locate the uterus. Two sides of the uterus were ligated, along with the vessels, by twine and $\sim 1 \mathrm{~cm}$ was left in the middle. This $1-\mathrm{cm}$ section of tissue was cut using scissors and placed in a sterile culture dish containing normal saline. The endometrium was removed using sterile microscopic tweezers and cut into fragments measuring $5 \times 5 \mathrm{~mm}$. These fragments were attached to the abdominal wall. The incision was stitched and smeared with iodophor. Rats were places onto heating pads to regain consciousness quickly.

Experimental groups. Following the induction of endometriosis, the rats were allowed to recover for 4 weeks, during which time they were not administered with any medication. Subsequently, 30 rats were divided into the following five experimental groups: Model, saline (equal volume of normal saline for each rat); $5 \mu \mathrm{M}$ RSG; $10 \mu \mathrm{M} \mathrm{RSG}$; and $20 \mu \mathrm{M}$ RSG. The abdomen of each rat was cut open and the corresponding treatments were administered via one-time treatment by injection directly into endometriotic implant $(100 \mu \mathrm{l})$ following anesthesia with isoflurane (5\% induction, $2 \%$ maintenance). The wounds were stitched up and smeared with iodophor, and the animals were sacrificed 2 weeks after the administration through decapitation following anesthesia with isoflurane.

Hematoxylin \& eosin $(H \& E)$ staining. Endometrium was collected from each animal and fixed in in $4 \%$ paraformaldehyde for $\sim 1$ week at $4^{\circ} \mathrm{C}$. Subsequently, the tissues were washed with sterile water for a couple of hours. The tissue was dehydrated using 70, 80 and 90\% ethanol solutions successively and mixed with equal quantities of ethanol and xylene. After 15 min incubation, the tissue was mixed with an equal quantity of xylene for $15 \mathrm{~min}$. These steps were repeated until the tissue appeared transparent. The tissue was then embedded in paraffin at room temperature for $5 \mathrm{~min}$ and sectioned at a thickness of $10 \mu \mathrm{m}$, and stained with $\mathrm{H} \& \mathrm{E}$ for $3 \mathrm{~min}$ at room temperature. Images were acquired using an inverted microscope (magnification, x200; Olympus Corporation).

Transmission electron microscopy. The endometrium was collected after the animals were executed and was fixed with $2.5 \%$ glutaraldehyde for over $2 \mathrm{~h}$ at room temperature and washed with $0.1 \mathrm{M}$ phosphoric acid solution three times. Next, the tissues were fixed with $1 \%$ osmic acid for $2-3 \mathrm{~h}$ at room temperature and washed with $0.1 \mathrm{M}$ phosphoric acid three times. The tissues were then washed with $50 \%$ ethyl alcohol, $70 \%$ ethyl alcohol, 90\% ethyl alcohol, 90\% ethyl alcohol and $90 \%$ acetone (v:v=1:1), and $90 \%$ acetone successively for 15-20 min. Next, the tissues were incubated with $100 \%$ acetone at room temperature three times for 15-20 min each. Acetone (100\%) and the embedding solution were incubated with the tissues for 3-4 h at room temperature. Finally, the tissues were successively embedded in $0.01 \%$ epoxy resin at $37^{\circ} \mathrm{C}$ overnight, $45^{\circ} \mathrm{C}$ for $12 \mathrm{~h}$, and $60^{\circ} \mathrm{C}$ for $48 \mathrm{~h}$. The solid tissue was cut into ultrathin sections $(100 \mathrm{~nm})$ and the slides were stained with lead citrate and uranyl acetate at room temperature for $5 \mathrm{~min}$. Ultrastructural endometrium changes were observed and images were captured using transmission electron microscopy (magnification: x1,000; JEM-1230; JEOL, Ltd.).

Immunohistochemistry. The endometrium was separated and fixed in $4 \%$ paraformaldehyde for $\sim 1$ week at $4^{\circ} \mathrm{C}$. The tissues were placed into a plate filled with pre-cooled normal saline. The tissue was embedded in paraffin, sectioned into $20 \mu \mathrm{m}$. The sections were blocking in $5 \%$ bovine serum albumin (Hyclone; Cytiva) at room temperature for $2 \mathrm{~h}$ and incubated with anti-cleaved caspase-3 antibody (dilution, 1:200; cat. no. ab32042; Abcam) and anti-VEGF antibody (dilution, 1:1,000; cat. no. bs-10853R; Bioss) at $4^{\circ} \mathrm{C}$ overnight. Samples were then washed with phosphate-buffered saline (PBS), and the slides were incubated with horseradish peroxidase (HRP)-conjugated goat anti-rabbit IgG (1:10,000; cat. no. A16104; Thermo Fisher Scientific, Inc.) at $37^{\circ} \mathrm{C}$ for $30 \mathrm{~min}$. After washing with PBS, the slides were dyed with DAB agent for 5-10 min and re-dyed with hematoxylin for $3 \mathrm{~min}$, both at room temperature. Images were obtained using an inverted microscope (magnification, x200; Olympus Corporation).

Reverse transcription-quantitative polymerase chain reaction ( $R T-q P C R)$. Total RNA from the collected endometrium cells was obtained using an RNA Extraction kit (Takara Biotechnology Co., Ltd.) and according to the manufacturer's protocols. Extracted RNA was quantified using a NanoDrop spectrophotometer (NanoDrop Technologies). cDNA was synthesized at $30^{\circ} \mathrm{C}$ for $10 \mathrm{~min}$ according to the instructions of the reverse transcriptase kit (CoWin Biosciences). SYBR Premix Ex Taq ${ }^{\mathrm{TM}}$ (Takara Biotechnology Co., Ltd.) and an Applied Bio-Rad CFX96 Sequence Detection system (Applied Biosystems) was used for real-time PCR. The cycling protocol was as follows: Pre-denaturation at $95^{\circ} \mathrm{C}$ for $10 \mathrm{~min}, 40$ cycles of $95^{\circ} \mathrm{C}$ for $12 \mathrm{sec}, 58^{\circ} \mathrm{C}$ for $30 \mathrm{sec}$ and $72^{\circ} \mathrm{C}$ for $30 \mathrm{sec} . P P A R \gamma$ and $M A T 2 A$ expression levels were determined by the threshold cycle $(\mathrm{Ct})$, and relative expression levels were calculated using the $2^{-\Delta \Delta \mathrm{Cq}}$ method after normalization with reference to the 
Table I. Primer sequences.

\begin{tabular}{llccc}
\hline Genes & \multicolumn{1}{c}{ Sequences $\left(5^{\prime}-3^{\prime}\right)$} & $\begin{array}{c}\text { Length of the } \\
\text { primer }(\mathrm{bp})\end{array}$ & $\begin{array}{c}\text { Length of the } \\
\text { product }(\mathrm{bp})\end{array}$ & $\begin{array}{c}\text { Annealing } \\
\text { temperature }\left({ }^{\circ} \mathrm{C}\right)\end{array}$ \\
\hline$P P A R \gamma F$ & CCCAGGTTTGCTGAATGTG & 18 & 197 & 57.8 \\
$P P A R \gamma R$ & TGTCTGTCTCCGTCTTCTTGAT & 20 & & 57 \\
$M A T 2 A F$ & TTGTGCCTGCGAAATACCT & 19 & 102 & 57.2 \\
$M A T 2 A R$ & CCCCAACCGCCATAAGT & 17 & 106 & \\
GAPDH $F$ & CAATGACCCCTTCATTGACC & 20 & & \\
GAPDH $R$ & GAGAAGCTTCCCGTTCTCAG & 20 & & \\
\hline
\end{tabular}

expression of U6 small nuclear RNA (11). GAPDH expression levels were used as negative controls. Primer information is listed in Table I.

Western blot analysis. The Nuclear and Cytoplasmic Protein Extraction kit (Beyotime Institute of Biotechnology) was used to isolate proteins from the tissues. After determining the concentration using the BCA method, approximately $35 \mu \mathrm{g}$ protein per lane was separated on $12 \%$ SDS-polyacrylamide gels. The separated proteins were transferred onto a polyvinylidene difluoride (PVDF) membrane (EMD Millipore). The membrane was blocked with $5 \%$ skimmed dry milk in TBST (Tris buffered saline/0.1\% Tween-20, pH 7.4) for $1 \mathrm{~h}$ at room temperature and incubated overnight with primary rabbit anti-human antibodies against PPAR $\gamma$ (cat. no. AF6284; Affinity Biosciences; dilution 1:1,500) and MAT2A (cat. no. ab189208, Abcam; dilution 1:1,000). A horseradish peroxidase-conjugated antibody against rabbit IgG (cat. no. ZB-2305, OriGene Technologies, Inc.; dilution $1: 5,000)$ was used as a secondary antibody. Blots were incubated with ECL reagents (Beyotime Institute of Biotechnology) and exposed using a Tanon 5200-multi to detect protein expression.

Statistical analysis. The data are expressed as the mean and standard deviation with six repeats. Statistically significant differences for continuous variables were determined using a one-way analysis of variance with the least significant difference test for normally distributed data. All testing was performed using GraphPad Prism 5 software (GraphPad Software, Inc.). $\mathrm{P}<0.05$ was considered to indicate a statistically significant difference.

\section{Results}

Effects of RSG on the pathological states of the endometrium. The endometriosis rat model in each group is shown in Fig. 1. Compared with the model group, the tumor weight in the RGS group was significantly decreased (vs. model; $\mathrm{P}<0.05$ ). This decrease was more significant at 10 and $20 \mu \mathrm{M}$ doses of RSG.

To investigate the impact of RSG on the pathological changes of endometria extracted from experimental rats, H\&E staining was performed. Three RSG dosages were used: 5, 10 and $20 \mu \mathrm{M}$. Transparent and red nodules were observed in the model group, and vasoganglion were present all over the nodules (Fig. 2). Columnar shaped endometrial epithelial hyperplasia was observed in the model and saline groups. Increased numbers of interstitial cells, with compact structure and abundant blood supply, were detected in model and NS groups. Compared with the model group, incomplete epithelial structure with sparse interstitial cells and loose structure was observed in the pathological images from RSG-treated groups. Inflammatory cells were involved in the tissues, and mainly included neutrophil granulocytes. The cells were filled with edema, with poor blood supply. The gland was filled with more vacuolar cells. These pathological results indicated that the endometrium was notably damaged by different RSG dosages.

Effects of RSG on the physiological structure of the endometrium. To investigate the effects of RSG on the growth of the endometrium, the subcellular structure in the tissues was observed using transmission electron microscopy. The results demonstrated that the tissue structure was integrated in the model and saline-treated groups (Fig. 3). Numerous vacuoles were formed within the endometrial tissue and classical morphological changes in apoptotic cells were observed in the RSG-treated groups.

Effects of RSG on VEGF and caspase-3 expression levels in the endometrium. To further investigate the potential mechanism of RSG on endometriosis, VEGF and cleaved caspase-3 expression levels were assessed by immunohistochemistry. As shown in Fig. 4, compared with the model group, expression of VEGF in endometria from rats treated with different RSG dosages decreased significantly (vs. model; $\mathrm{P}<0.05$ ) and caspase-3 expression increased (vs. model; P<0.05; Fig. 4).

Effects of RSG on PPAR $\gamma$ and MAT2A expression levels in the endometrium. To investigate the effects of RSG on the endometriosis at the molecular level, the expression of MAT2A, a major clinical biomarker for endometriosis, was assessed using RT-qPCR and western blotting. Compared with the model group, the PPAR $\gamma$ expression in the endometria of rats treated with RSG increased significantly (vs. model, $\mathrm{P}<0.05$; Fig. 5). These results indicated that RSG, which is a PPAR $\gamma$ agonist, may upregulate PPAR $\gamma$ expression in this tissue. By contrast, MAT2A expression was decreased in the endometrium of rats treated with RSG, compared with that observed in the model group $(\mathrm{P}<0.05)$.

\section{Discussion}

Numerous factors, including immunoreactions, inflammation and angiogenesis, contribute toward the development and 


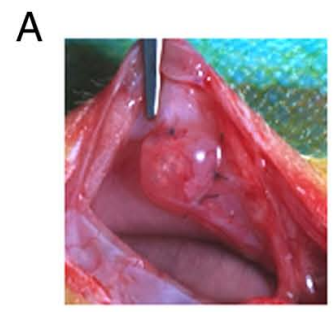

Model

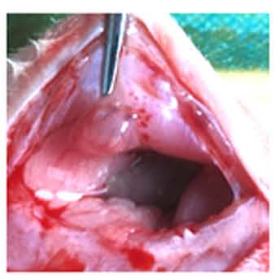

$10 \mu \mathrm{M}$

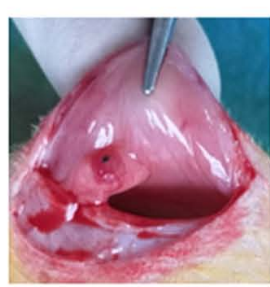

Saline

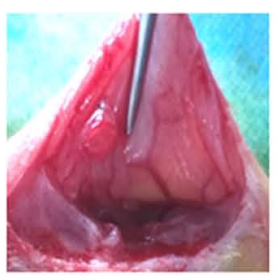

$20 \mu \mathrm{M}$

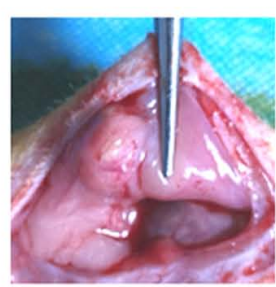

$5 \mu \mathrm{M}$
B
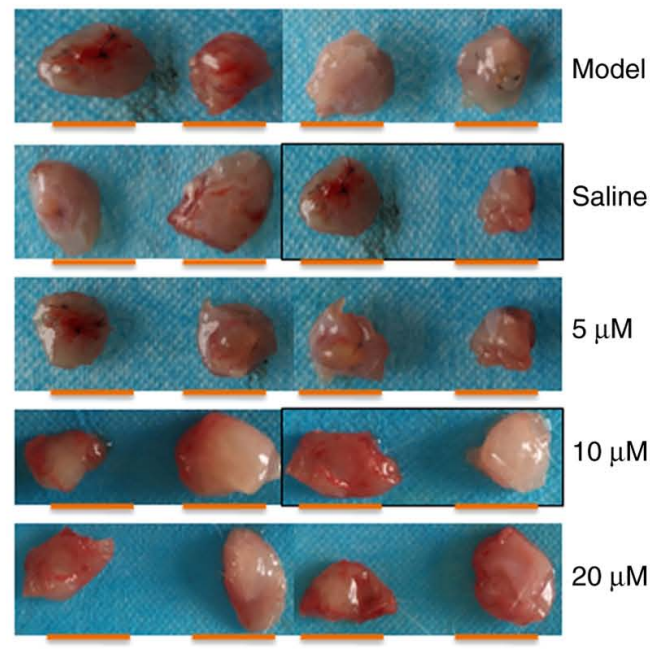

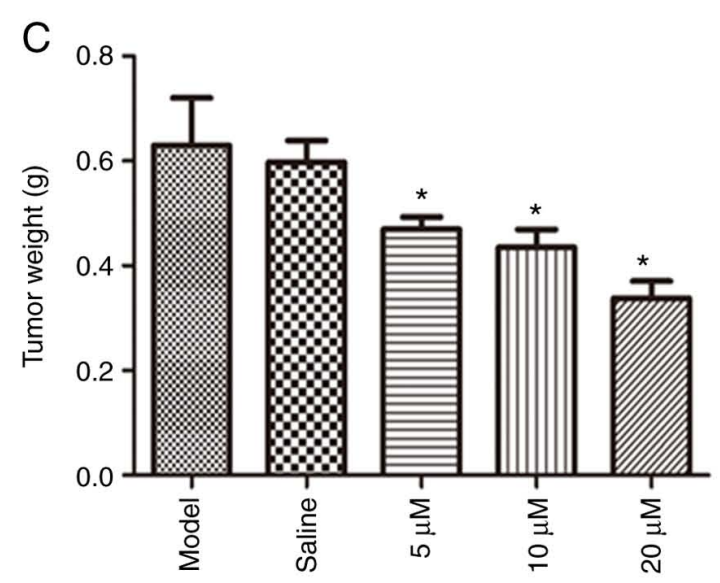

Figure 1. Endometriosis rat models in each treatment group. (A) Endometriosis-related morphological changes. (B) Representative images of tumors; scale bar, $8 \mathrm{~mm}$. (C) Quantitative data of the tumor weight. " $\mathrm{P}<0.05$, vs. model group.

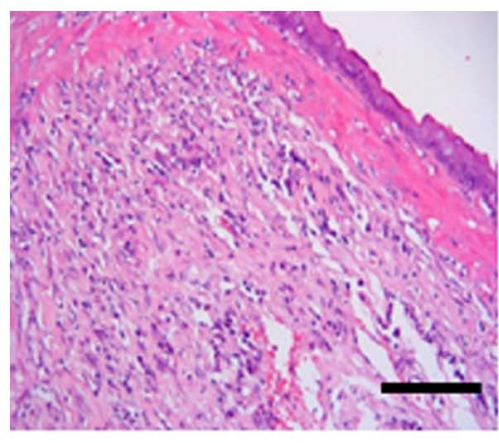

Model

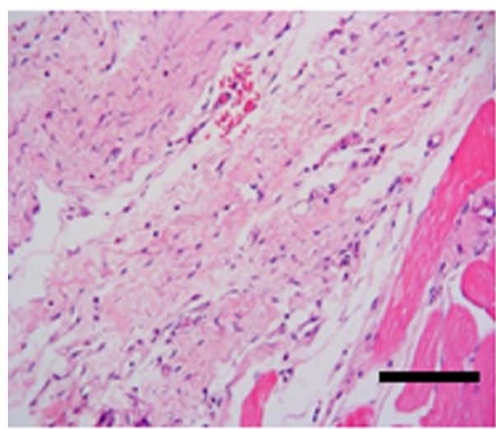

$10 \mu \mathrm{M}$

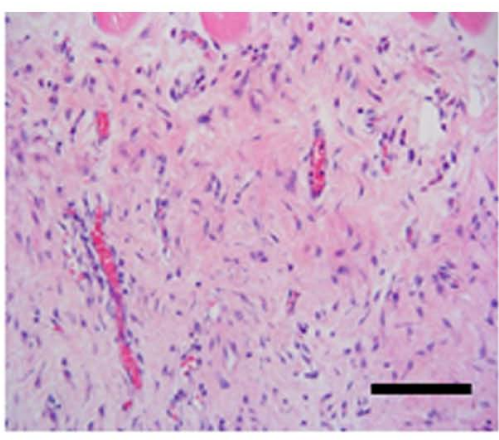

Saline

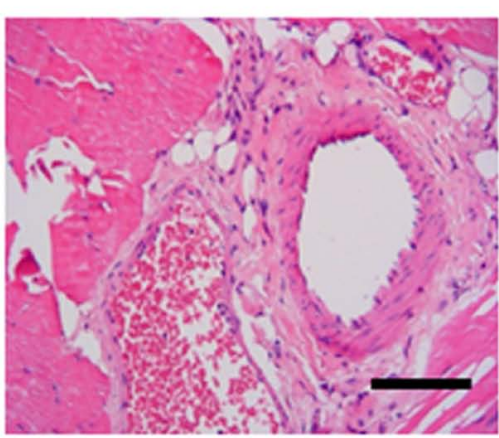

$20 \mu \mathrm{M}$

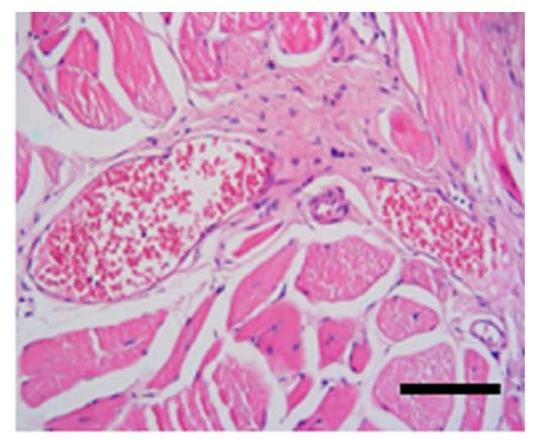

$5 \mu \mathrm{M}$

Figure 2. Hematoxylin and eosin staining of ectopic endometrial tissue from rats in each group. Scale bar=100 $\mu \mathrm{m}$; magnification, $\mathrm{x} 200$ ( $\mathrm{n}=6$ ). 


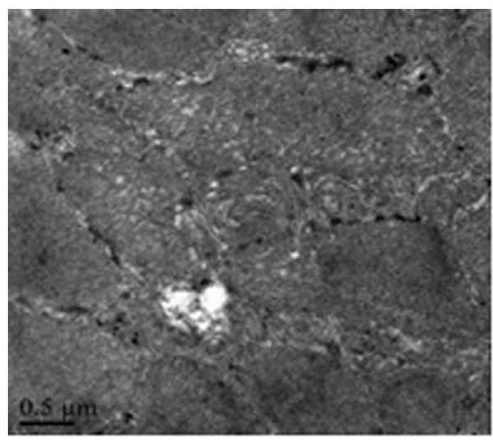

Model

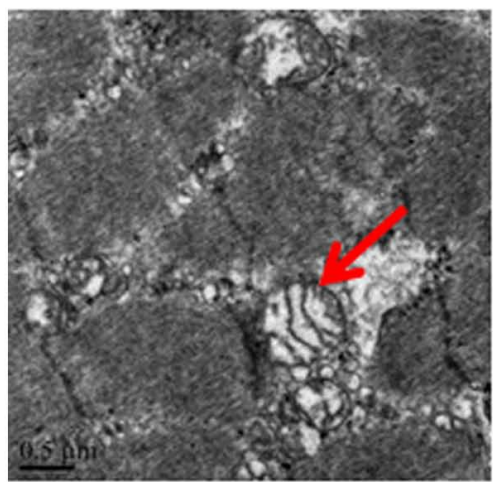

$10 \mu \mathrm{M}$

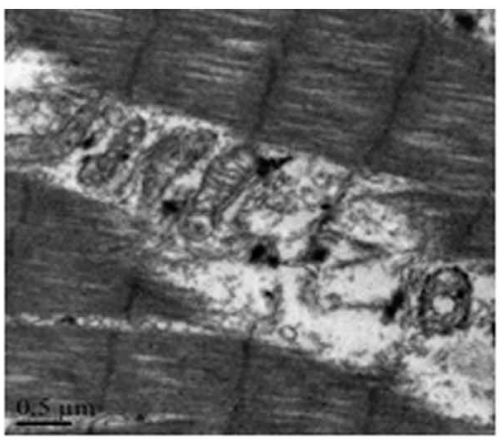

Saline

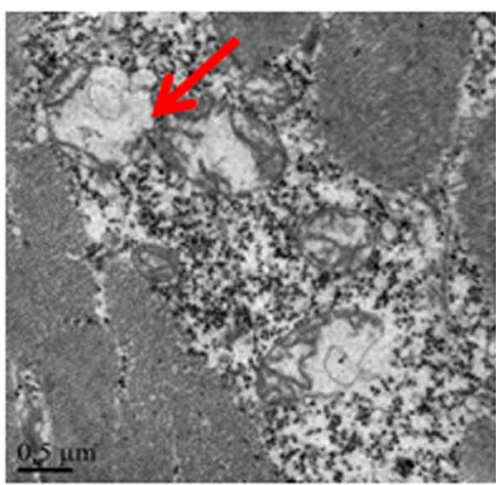

$20 \mu \mathrm{M}$

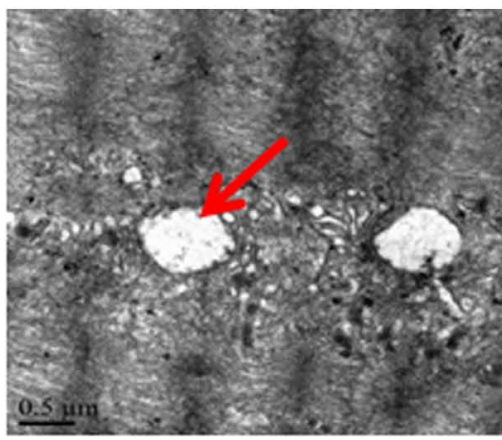

$5 \mu \mathrm{M}$

Figure 3. Transmission electron microscopy images of ectopic endometrial tissue from rats in each group. Arrows indicate pathological changes.

A

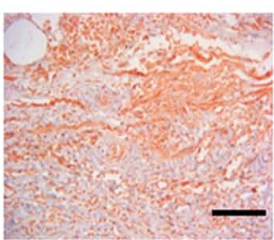

Model

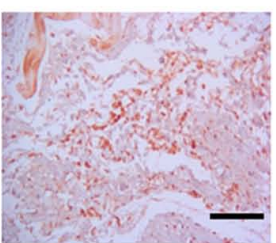

$10 \mu \mathrm{M}$

B

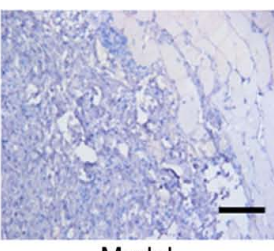

Model

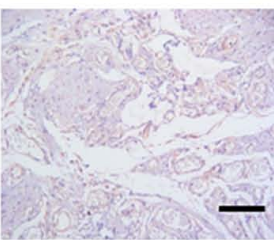

$10 \mu \mathrm{M}$

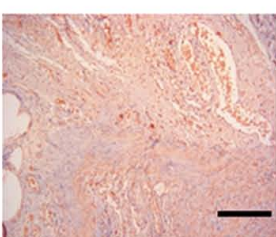

Saline

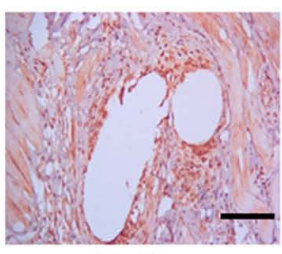

$20 \mu \mathrm{M}$

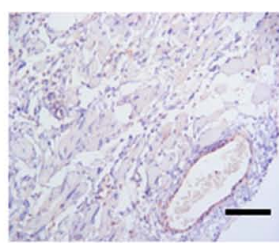

Saline

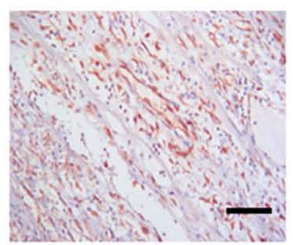

$20 \mu \mathrm{M}$

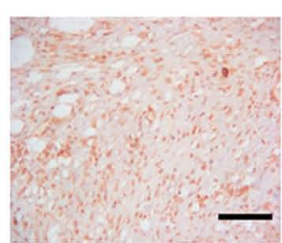

$5 \mu \mathrm{M}$

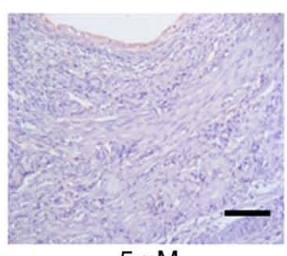

$5 \mu \mathrm{M}$
C

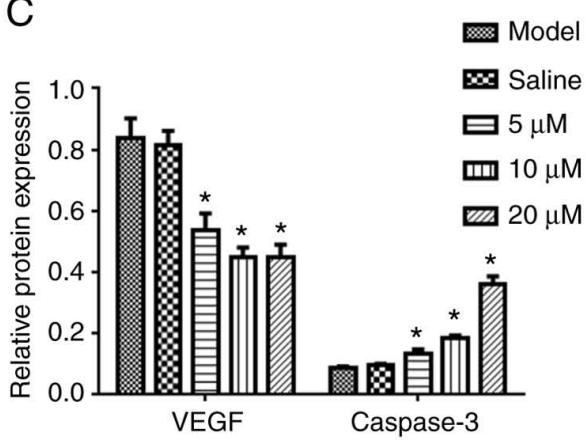

Figure 4. Effects of RSG on VEGF and caspase-3 expression in the endometrium. (A) VEGF expression was detected by immunohistochemistry in ectopic endometrium tissue from rats in each group. (B) Caspase-3 expression was detected by immunohistochemistry in ectopic endometrial tissue from rats in each group. (C) Quantitative VEFG and caspase-3 expression. * $\mathrm{P}<0.05$, vs. model group. RSG, rosiglitazone. 

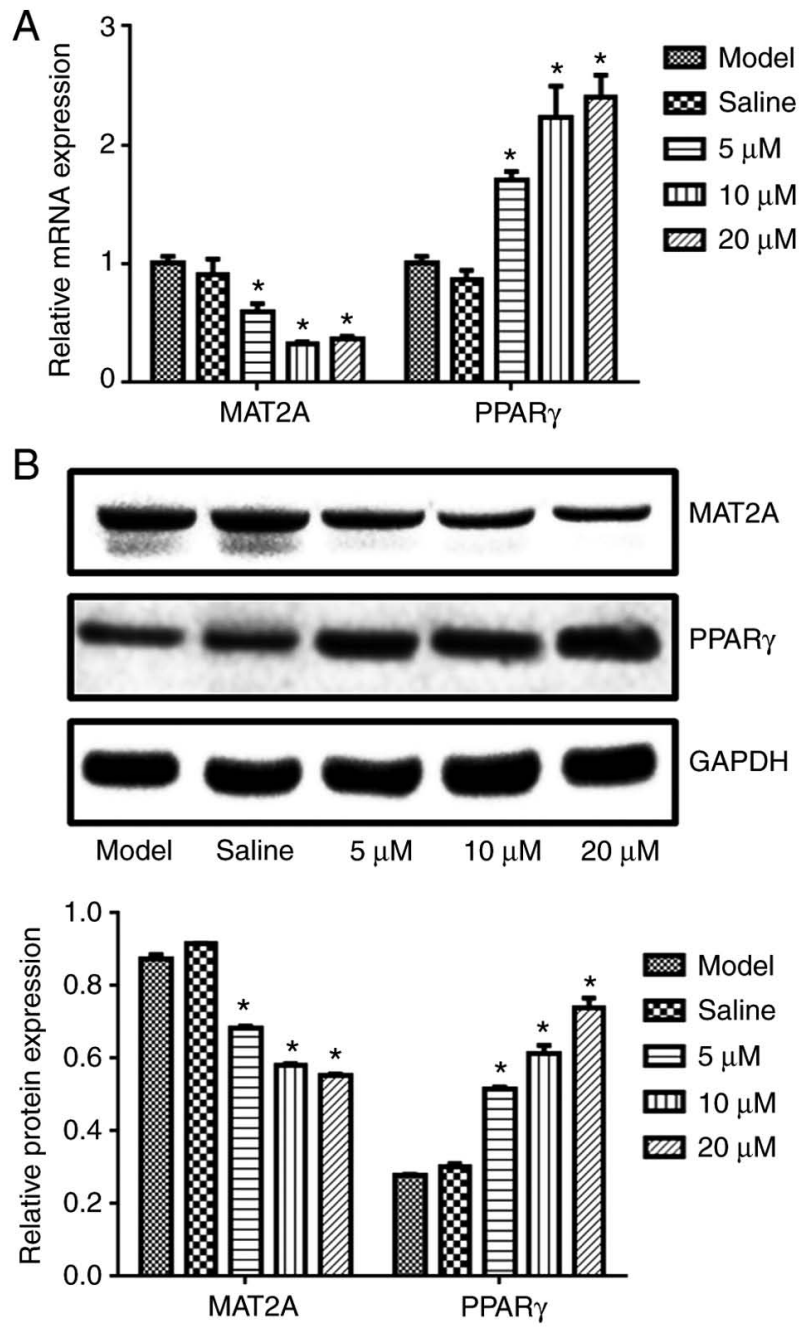

Figure 5. Effects of RSG on PPAR $\gamma$ and MAT2A expression levels in the endometrium. (A) PPAR $\gamma$ and MAT2A expression levels in ectopic endometrial tissue from rats in each group were detected by reverse transcription-quantitative polymerase chain reaction. (B) PPAR $\gamma$ and MAT2A expression in ectopic endometrial tissue from rats in each group were detected by western blot analysis. ${ }^{*} \mathrm{P}<0.05$, vs. model group. RSG, rosiglitazone.

progression of endometriosis (12). Therapeutically, the formation and progression of endometriosis may be inhibited by regulating these factors $(13,14)$. Given the difficulties and limits to reflecting the integrity of biological processes, including endometriosis, in isolated cells, a rat endometriosis model was utilized in this study (10). This approach enabled the assessment of the general pattern of transplanted endometrial growth in the abdomen, and investigation of the optimal action time of drugs by observing the dynamic pathological and structural changes in the endometrium of the endometriosis animal model. SD rats were selected because of their fast reproductive cycle and high level of homology with humans. Endometriosis was established in rats by transplanting the endometrium to their abdominal wall. Clear endometriosis lesions, including protuberances, were observed in the abdomen. Along with variations in $\mathrm{H} \& \mathrm{E}$ staining results in the endometrium tissues, the results of the present study indicated that the endometriosis model was successfully established in SD rats.

PPAR $\gamma$ agonists are potential inhibitors of cell proliferation (15) and may induce apoptosis (16). PPAR $\gamma$ agonists also exert anti-angiogenesis properties by downregulating the expression of vascular growth factors (17). Research using the endometriosis animal model revealed that application of the RSG PPAR $\gamma$ agonist may significantly inhibit angiogenesis within the endometrium and shrink endometriosis lesions $(8,18,19)$. In the present study, to investigate the impact of RSG on endometriosis, an endometriosis model was successfully established in rats. The results indicated that the size of the endometrium was diminished as the RSG concentration increased. The observation of pathological states and sub-cellular structure revealed numerous vacuoles and the classic morphological changes of apoptotic cells in the endometrium following RSG treatment. The degeneration of endometrium may be induced by PPAR $\gamma$ activation (20). Nenicu et al reported that the therapeutic effects of Telmisartan on endometriosis in mice were associated with angiotensin II receptor inhibition and PPAR $\gamma$ signal pathway activation (19). In a mouse model of endometriosis, the volume of the endometriosis injury site in mice treated with RSG was much smaller than that in model mice (21). Lebovic et al reported that the growth of ectopic endometrial tissue was significantly inhibited in baboons by oral administration of RSG (22). These reports indicated that the growth of ectopic endometrium may be suppressed by PPAR $\gamma$ activation. These results demonstrated that the PPAR $\gamma$ signal pathway was activated by treatment with RSG, which inhibited the expression of MAT2A.

Immune cells, adhesion molecules, extracellular matrix metalloproteinase and pro-inflammatory cytokines activate/alter the peritoneal microenvironment, creating conditions for differentiation, adhesion, proliferation and survival of ectopic endometrial cells (23-25). Meanwhile, angiogenesis is an important factor that induces the paroxysm of endometriosis. The establishment and maintenance of the blood supply between ectopic endometrium and surrounding are a precondition for the establishment of endometriosis. The factors involved in angiogenesis within ectopic endometrium include epidermal growth factor (EGF), vascular endothelial growth factor (VEGF), angiogenin-II and transformed growth factor $\beta$ (TGF $\beta$ ). Among these factors, VEGF is of great importance and may induce angiogenesis directly. VEGF is highly expressed in ectopic endometrial and mesenchymal cells (26) and VEGF expression in ectopic endometrial cells is significantly decreased by RSG treatment (27). RSG treatment also decreases the vessel density within the ectopic endometrium (21). In the present study, VEGF expression in ectopic endometrial tissues markedly declined following RSG treatment. Taken together, these results implied that the inhibition of ectopic endometrial growth by PPAR $\gamma$ activation may be associated with the decreased VEGF expression.

Caspase-3 is a key apoptotic protease in mammals, and serves a central role in the apoptotic cascade reaction pathway (28). Caspase-3 is activated when cells encounter apoptotic stimulants, which then activate other proteins in the apoptotic pathway to induce apoptosis (29). The therapeutic effects of cyclooxygenase- 2 on endometriosis are associated with apoptosis mediated by caspase-3 activation (30). The ectopic endometrial cells refluxed to the pelvic cavity were still active because of the inhibition of ectopic endometrial cell apoptosis, which was beneficial to the plantation and growth 
of ectopic endometrium and induced endometriosis (31). In the present study, caspase-3 expression levels significantly increased following RSG treatment. These results indicated that the therapeutic effects of RSG on endometriosis may be associated with apoptosis in ectopic endometrial cells mediated by the activation of caspase-3. Nevertheless, the exact signaling pathways involved in RSG-induced apoptosis and more persuasive evidence to support the fact that angiogenesis should be tested in future.

In conclusion, RSG impacts the development and progression of endometriosis, likely by inhibiting angiogenesis and inducing apoptosis.

\section{Acknowledgements}

Not applicable.

\section{Funding}

The present study was supported by grants from the National Natural Science Foundation of China (grant no. 81560247).

\section{Availability of data and materials}

The datasets used and/or analyzed during the current study are available from the corresponding author on reasonable request.

\section{Authors' contributions}

SZ, LZ, QL, XY, QM and MC performed the experiments and analyzed the data. SZ and QC designed the study and wrote the manuscript. All authors read and approved the final manuscript.

\section{Ethics approval and consent to participate}

All animal experiments were authorized by the Ethical Committee of The First Affiliated Hospital of Nanchang University and performed following the guidelines for the care and use of laboratory animals and the principles of laboratory animal care and protection.

\section{Patient consent for publication}

Not applicable.

\section{Competing interests}

The authors declare that they have no competing interests.

\section{References}

1. Arablou T and Kolahdouz-Mohammadi R: Curcumin and endometriosis: Review on potential roles and molecular mechanisms. Biomed Pharmacother 97: 91-97, 2018.

2. Zhao RH: Strategies for activating blood circulation-regulating gan (Liver)-tonifying shen (Kidney) sequential therapy of endometriosis-associated infertility. Chin J Integr Med 25: 243-245, 2019.

3. Zhu H, Cao XX, Liu J and Hua H: MicroRNA-488 inhibits endometrial glandular epithelial cell proliferation, migration, and invasion in endometriosis mice via Wnt by inhibiting FZD7. J Cell Mol Med 23: 2419-2430, 2019.
4. Lebovic DI, Kavoussi SK, Lee J, Banu SK and Arosh JA: PPAR activation inhibits growth and survival of human endometriotic cells by suppressing estrogen biosynthesis and PGE2 signaling. Endocrinology 154: 4803-4813, 2013.

5. Clemenza S, Sorbi F, Noci I, Capezzuoli T, Turrini I, Carriero C, Buffi N, Fambrini M and Petraglia F: From pathogenesis to clinical practice: Emerging medical treatments for endometriosis. Best Pract Res Clin Obstet Gynaecol 51: 92-101, 2018

6. Jafarabadi M, Salehnia M and Sadafi R: Evaluation of two endometriosis models by transplantation of human endometrial tissue fragments and human endometrial mesenchymal cells. Int J Reprod Biomed 15: 21-32, 2017.

7. Liu X, Yu H, Yang L, Li C and Li L: 15-Deoxy-D $(12,14)$-prostaglandin $J(2)$ attenuates the biological activities of monocyte/macrophage cell lines. Eur J Cell Biol 91: 654-661, 2012.

8. Demirturk F, Aytan H, Caliskan AC, Aytan P and Koseoglu DR: Effect of peroxisome proliferator-activated receptor-gamma agonist rosiglitazone on the induction of endometriosis in an experimental rat model. J Soc Gynecol Investig 13: 58-62, 2006.

9. Dworzanski T, Celinski K, Korolczuk A, Slomka M, Radej S, Czechowska G, Madro A and Cichoz-Lach H: Influence of the peroxisome proliferator-activated receptor gamma (PPAR- $\gamma$ ) agonist, rosiglitazone and antagonist, biphenol-A-diglicydyl ether (BADGE) on the course of inflammation in the experimental model of colitis in rats. J Physiol Pharmacol 61: 683-693, 2010.

10. Li Z, Liu H, Lang J, Zhang G and He Z: Effects of cisplatin on surgically induced endometriosis in a rat model. Oncol Lett 16: 5282-5290, 2018.

11. Livak KJ and Schmittgen TD: Analysis of relative gene expression data using real-time quantitative PCR and the 2(-Delta Delta C(T)) method. Methods 25: 402-408, 2001.

12. Zubrzycka A, Zubrzycki M, Perdas E and Zubrzycka M: Genetic, epigenetic, and steroidogenic modulation mechanisms in endometriosis. J Clin Med 9: 1309, 2020

13. Zhou WJ, Yang HL, Shao J, Mei J, Chang KK, Zhu R and Li MQ: Anti-inflammatory cytokines in endometriosis. Cell Mol Life Sci 76: 2111-2132, 2019.

14. Zani ACT, Valerio FP, Meola J, da Silva AR, Nogueira AA, Candido-Dos-Reis FJ, Poli-Neto OB and Rosa-E-Silva JC: Impact of bevacizumab on experimentally induced endometriotic lesions: Angiogenesis, invasion, apoptosis, and cell proliferation. Reprod Sci 27: 1943-1950, 2020.

15. Loy CJ, Evelyn S, Lim FK, Liu MH and Yong EL: Growth dynamics of human leiomyoma cells and inhibitory effects of the peroxisome proliferator-activated receptor-gamma ligand, pioglitazone. Mol Hum Reprod 11: 561-566, 2005.

16. Heaney AP, Fernando M and Melmed S: PPAR-gamma receptor ligands: Novel therapy for pituitary adenomas. J Clin Invest 111: 1381-1388, 2003.

17. Panigrahy D, Huang S, Kieran MW and Kaipainen A: PPARgamma as a therapeutic target for tumor angiogenesis and metastasis. Cancer Biol Ther 4: 687-693, 2005.

18. Aytan H, Caliskan AC, Demirturk F, Aytan P and Koseoglu DR: Peroxisome proliferator-activated receptor-gamma agonist rosiglitazone reduces the size of experimental endometriosis in the rat model. Aust N Z J Obstet Gynaecol 47: 321-325, 2007.

19. Nenicu A, Korbel C, Gu Y, Menger MD and Laschke MW: Combined blockade of angiotensin II type 1 receptor and activation of peroxisome proliferator-activated receptor- $\gamma$ by telmisartan effectively inhibits vascularization and growth of murine endometriosis-like lesions. Hum Reprod 29: 1011-1024, 2014.

20. Chang HJ, Lee JH, Hwang KJ, Kim MR and Yoo JH: Peroxisome proliferator-activated receptor $\mathrm{g}$ agonist suppresses human telomerase reverse transcriptase expression and aromatase activity in eutopic endometrial stromal cells from endometriosis. Clin Exp Reprod Med 40: 67-75, 2013

21. Olivares C, Ricci A, Bilotas M, Barañao RI and Meresman G: The inhibitory effect of celecoxib and rosiglitazone on experimental endometriosis. Fertil Steril 96: 428-433, 2011.

22. Lebovic DI, Mwenda JM, Chai DC, Santi A, Xu X and D'Hooghe T: Peroxisome proliferator-activated receptor-(gamma) receptor ligand partially prevents the development of endometrial explants in baboons: A prospective, randomized, placebo-controlled study. Endocrinology 151: 1846-1852, 2010. 
23. Lagana AS, Garzon S, Götte M, Viganò P, Franchi M, Ghezzi F and Martin DC: The pathogenesis of endometriosis: Molecular and cell biology insights. Int J Mol Sci 20: 5615, 2019.

24. Lagana AS, Salmeri FM, Ban Frangez H, Ghezzi F, Vrtacnik-Bokal E and Granese R: Evaluation of M1 and M2 macrophages in ovarian endometriomas from women affected by endometriosis at different stages of the disease. Gynecol Endocrinol 36: 441-444, 2020.

25. Lagana AS, Salmeri FM, Vitale SG, Triolo O and Götte M: Stem cell trafficking during endometriosis: May epigenetics play a pivotal role? Reprod Sci 25: 978-979, 2018.

26. Rashidi BH, Sarhangi N, Aminimoghaddam S, Haghollahi F, Naji T, Amoli MM and Shahrabi-Farahani M: Association of vascular endothelial growth factor (VEGF) Gene polymorphisms and expression with the risk of endometriosis: A case-control study. Mol Biol Rep 46: 3445-3450, 2019.

27. Cazzaniga A, Locatelli L, Castiglioni S and Maier J: The contribution of EDF1 to PPAR $\gamma$ transcriptional activation in VEGF-treated human endothelial cells. Int J Mol Sci 19: 1830, 2018.
28. Li J, Yang S and Zhu G: Postnatal calpain inhibition elicits cerebellar cell death and motor dysfunction. Oncotarget 8: 87997-88007, 2017.

29. Wang Y, Gao W, Shi X, Ding J, Liu W, He H, Wang K and Shao F Chemotherapy drugs induce pyroptosis through caspase-3 cleavage of a gasdermin. Nature 547: 99-103, 2017.

30. Das I and Saha T: Effect of garlic on lipid peroxidation and antioxidation enzymes in DMBA-induced skin carcinoma. Nutrition 25: 459-471, 2009.

31. Park JH, Lee SK, Kim MK, Lee JH, Yun BH, Park JH, Seo SK, Cho SH and Choi YS: Saponin extracts induced apoptosis of endometrial cells from women with endometriosis through modulation of miR-21-5p. Reprod Sci 25: 292-301, 2018

(i) $($ This work is licensed under a Creative Common Attribution-NonCommercial-NoDerivatives 4.0 International (CC BY-NC-ND 4.0) License. 